\title{
Impact of Recent Trends in Drug Discovery and Development
}

\author{
Neema Bisht and Archana N Sah* \\ Department of Pharmaceutical Sciences, Bhimtal Campus, Kumaun University, India
}

Submission: January 16, 2019 Published: March 13, 2019

"Corresponding author: Archana N Sah, Department of Pharmaceutical Sciences, Bhimtal Campus, Kumaun University, India

\begin{abstract}
Discovery and development of a new drug is a very complex process as it takes long duration and various resources. The practice of drug discovery has been speeding up with the use of newer advanced techniques to increase the efficiency of the process. Various recent technologies like bioinformatics, computer-aided drug design (CADD), combinatorial chemistry has considerably extended its range of applications and spanning almost all stages in the drug discovery process. Chemical compounds can be screened out for their biological activity with target through high-throughput screening (HTS). Advanced technologies are using successfully now days due to speed up, low expenses and greater success rates in drug development. The main objective of this mini review is to highlight the utility of various recent trends in drug discovery.
\end{abstract}

Keywords: Drug discovery; CADD; Combinatorial chemistry; HTS

\section{Introduction}

\section{Drug Discovery and Development}

Drug discovery is a very complex, tedious process and it includes inter disciplinary efforts for designing an effective and commercially feasible drug. The discovery as well as development of any drug takes many years because it begins with scientific studies like determination of disease, determination of specific target receptor and determination of active compound from the mass of compounds through various screening methods, etc. [1].

\section{Recent Trends in Drug Discovery and Development}

In pharmaceutical, medicinal as well as in other scientific research; a computer plays a very important role, even in development of new compound in quest for better therapeutic agents [2]. Combination of rational drug design and structure biology leads to the discovery of novel therapeutic agents. The field of in-silico drug designing (CADD) is a rapidly burgeoning area which is an inventive process of finding novel leads as well as aids in the process of drug discovery and development research. The explosion of bioinformatics, cheminformatics, genomics, proteomics, and structural information has provided approximately hundreds of newer targets as well as newer ligands with advantages such as cost saving, time-to-market, in-sight knowledge of drug-receptor interactions and speed up drug discovery and development, etc. [3].
Various approaches of CADD are used as promising techniques according to their need, like structure-based drug design and ligand-based drug design. These both methods can be applied with virtual screening and molecular docking for identification and optimization of lead molecules $[4,5]$. Likewise; combinatorial chemistry is used to synthesize, purify, analyse, and screen large numbers of chemical compounds, faster and cheaper than was previously possible with traditional methods of synthesis. Large number of compounds can be synthesized through combinatorial chemistry in laboratory; also, combinatorial library can be generated through various database tools like SmiLib, GLARE, ChemT, CLEVER, Library synthesizer etc. [6,7].

Ligands (inhibitors, activators, agonists, antagonists or substrate analogues) can be identified using conventional hitidentifying methods such as HTS assays or employing various CADD techniques. Because of their respective strengths and weaknesses for drug discovery, HTS and CADD techniques are often seen as complementary to each other [7-9]. Screening of compounds includes two different methods which are widely used in the pharmaceutical industry for finding various hits which are: high-throughput screening (compound synthesis as well as screening against cell based or protein based assays) and virtual screening [10]. 
Currently, the rapid developments in high-throughput screening technologies as well as combinatorial chemistry have provided an environment to expedite the drug discovery process by enabling huge libraries of compounds to be screened and synthesized in a short time. Consequently, various approaches have been developed to shorten the research process and reduce the expenses and risk of failure for drug discovery. Bioinformatics and CADD are one of the most effective methods for reaching these goals $[11,12]$.

Briefly; impacts of various recent trends in drug discovery development process are

a) Increases the efficiency of drug discovery process

b) Cost saving

c) Time-to-market (Reduces the time from product development to available in market)

d) Insight of drug-receptor interaction

e) It makes the people understand the complex mathematical and statistical equation in simple form

f) Rapid and larger number of chemical compounds synthesis in laboratory as well as compound library generation with databases through combinatorial chemistry

g) Screening for larger number of compounds against desired biological activity through HTS

h) Higher success rates of newer drugs reaching the market

i) Development of promising drug candidate for desirable properties etc. $[13,14]$.

\section{Discussion}

This mini review highlights advancement in drug discovery and development. This review is dedicated on the recent trends like, identification of newer targets with their structural information, development of newer lead molecules through the concept of rational drug design, high-throughput screening, genomics, proteomics, as well as combinatorial chemistry approaches.

\section{Conclusion}

Drug discovery and development is witnessing a golden era since the introduction of high-throughput screening, bioinformatics, in-silico drug design, genomics, proteomics and combinatorial chemistry etc. Recent technologies are very much effective in drug development and discovery process and with the current successes there might be a promising future for development of a better drug candidate.

\section{References}

1. Bisht N, Singh BK (2018) Role of Computer-aided drug design in drug development and drug discovery. Int J Pharm Sci Res 9(4): 1405-1415.

2. Joseph T L, Namasivayam V, Poongavanam V, Kannan, S (2017) In-silico approaches for drug discovery and development. Int J Bio Sci 3: 3-74.

3. Dutta S, Sachann K (2017) Computer-aided drug design- a new approach in drug design and discovery. Int J Pharm Sci Rev Res 4: 146151.

4. Hoque I, Chatterjee A, Bhattacharya S, Biswas R (2017) An approach of computer-aided drug design (CADD) tools for in-silico pharmaceutical drug design and development. Int J Adv Res Biol Sci 4(2): 60-71.

5. Syed SI, Gilani Sadaf JG (2017) Computer-aided drug design: A novel looms to Drug discovery. Org Medi Chem IJ 1(4): 555-567.

6. Campbell IB, Macdonald SJ, Procopiou PA (2018) Medicinal chemistry in drug discovery in big pharma: past, present and future. Drug Discov Today 23(2): 219-234.

7. Xiang M, Cao Y, Fan W, Chen L, Mo Y (2012) Computer-aided drug design: lead discovery and optimization. Comb Chem \& Highthroughput Screen 15(4): 328-337.

8. Shekhar C (2008) In-silico pharmacology: Computer-aided methods could transform drug development. Chem \& Biol 15(5): 413-414.

9. Rao VS, K Srinivas (2011) Modern drug discovery process: an in-silico approach. J Bioinform Seq Anal 3(5): 89-94.

10. Gupta S, Basu A, Jaiswal A, Mishra N (2018) Computational methods in drug discovery. Int J Pharm Sci Res 9(10): 4102-4108.

11. Ou-Yang S, Lu JY, Kong XQ Liang ZJ, Luo C, et al. (2012) Computational drug discovery. Acta Pharmacol Sin 33(9): 1131-1140.

12. Athar M, Das AJ (2012) Current trends in drug discovery: target identification to clinical development of the drug. Int Res J Pharm 3(4): 23-27.

13. Hamad ON, Amran SIB, Sabbah AM (2018) Drug discovery-yesterday and tomorrow: The Common Approaches in Drug Design and Cancer. Cell \& Cellular Life Sci J 3(1): 000119.

14. Sathyaraj A (2011) Recent trends in pharmaceutical chemistry for drug discovery. Int J of Res in Pharm and Chem 1(3): 437-441. 


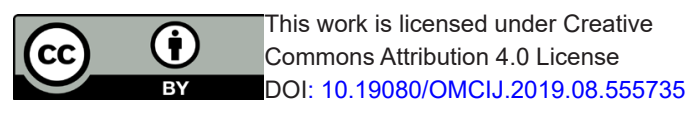

\begin{tabular}{l} 
Your next submission with Juniper Publishers \\
will reach you the below assets \\
- Quality Editorial service \\
- Swift Peer Review \\
- Reprints availability \\
- E-prints Service \\
- Manuscript Podcast for convenient understanding \\
- Global attainment for your research \\
- Manuscript accessibility in different formats \\
( Pdf, E-pub, Full Text, Audio) \\
- Unceasing customer service \\
Track the below URL for one-step submission \\
https://juniperpublishers.com/online-submission.php \\
\hline
\end{tabular}

